FORTHCOMING IN AXIOMATHES. PLEASE DO NOT CIRCULATE OR QUOTE: IF YOU'D LIKE TO RECEIVE THE FINAL DRAFT, CONTACT ME AT BRMEINERTSEN@GMAIL.COM

\title{
REINACH AND ARMSTRONGIAN STATE OF AFFAIRS ONTOLOGY
}

\section{Introduction}

Many views of the phenomenological realist Adolf Reinach are summarized in his (1911), which, importantly, also includes the clearest formulation of his metaphysics and ontology of Sachverhalte. Roughly, Sachverhalte are what is called states of affairs in contemporary analytic metaphysics. This paper attempts to bring Reinach's ontology of states of affairs as it is found in his (1911) into a conversation with the state of affairs ontology developed by Armstrong in $A$ World of States of Affairs and elsewhere, and more generally with the Armstrongian state of affairs ontology, or Armstrongian SOA-ontology, of Meinertsen (2018). The states of affairs of this ontology are instantiations of concrete universals by concrete particulars, and include monadic states of affairs, such as this rose's being red, and polyadic (relational) states of affairs, such as Edinburgh's being north of London. These states of affairs are concrete entities, as concrete and 'this-worldly' as the concrete objects they are about. Reinach's ontology of states of affairs is, however, much more ontologically 'abundant' than the one typically found in the Armstrongian tradition. But an equally abundant ontology of states of affairs occurs in the work of certain contemporary philosophers, notably Roderick Chisholm (e.g. 1970; 1971). However, as conventional wisdom among metaphysicians has it - correctly, in my view - Chisholm's states of affairs are very similar to propositions, or perhaps even identical to them. These entities - let us call them 'propositional states of affairs' (Betti 2015) - only really share their name with the sparse and concrete states of affairs of Armstrongian SOA-ontology. If Reinach's states of affairs are similar to Chisholm's, looking at them from the point of Armstrongian SOA-ontology might thus at first seem like comparing apples and oranges. As we shall see, Reinach's states of affairs are indeed similar to Chisholm's in several important respects. ${ }^{1}$ Nonetheless, some of their features can be taken as if they are alleged features or roles of concrete states of affairs, and hence Reinach presents us - to some extent - with a competitor to Armstrongian SOA-ontology. Roughly speaking, I shall argue that Reinach prompts us to ask if this ontology, in its most sparse form, is too sparse; specifically, if it should accept negative states of affairs. (Similarly, it prompts us to

\footnotetext{
${ }^{1}$ For the opposing view, see e.g. DuBois (1995, pp. 74-75).
} 
consider if should accept non-factual states of affairs, though this is a question that is beyond the scope of the present paper.) As I shall show, the answer to this question is a qualified 'yes'.

\section{Reinach and propositional states of affairs}

To repeat, I make the charge that, roughly, Reinach's states of affairs in several respects are very similar to propositions, i.e. that Reinachian states of affairs are propositional. I use the term 'propositions' and its derivatives for the entities that, in line with the standard contemporary sense, are the contents of declarative sentences (statements, assertions) and the objects of propositional attitudes. On some views, they are also bearers of truth and falsity. One of their hallmarks is that they are abstract ('Platonic') entities, i.e. neither spatially nor temporally located. As intimated above, I hold that propositional states of affairs are likewise abstract. In fact, in this paper, I shall take it to be a necessary and sufficient condition for a state of affairs being propositional that it is abstract. In addition to being abstract, propositional states of affairs are usually abundant Reinach's certainly are. But perhaps they need not be - this is a question I fortunately do not have to address in this paper - so I shall not use this a criterion for them. However, it is actually not clear whether or not Reinach's states of affairs are abstract. I do not think Reinach himself offers any straightforward help with answering this question in his (1911). Yet the view that his states of affairs are abstract is not uncommon. For example, Arkadiusz Chrudzimski asserts that Reinach 'developed an extremely Platonic approach' (2012, p. 107). But other commentators, e.g. Kimberly Jaray (2007, pp. 123ff), vehemently opposes it. Jaray, following phenomenological tradition, uses the term 'real' for concreta and 'ideal' for abstracta. Paradigm examples of 'real' and 'ideal' entities are ordinary objects and propositions, respectively. Her claim now is that Reinach's states of affairs are neither 'real' nor 'ideal', and hence neither concrete nor abstract. This surprising claim is suggested more or less explicitly by how she defines them:

States of affairs [Reinach's] are essential connections that exist between the thing judged and the properties judged - the being red of the rose - and thus are different from the actual rose and different from the proposition 'that rose is red' $(2007$, p. 96)

Whether we are considering Reinach's or some other ontology (except perhaps a 'Leibnizian' one), I think it is a tad confused to define contingent states of affairs, such as the rose's being red, as 
'essential connections'; but fortunately we can ignore that part of the passage. ${ }^{2}$ However, the second clause, which she apparently thinks follows from the first, clearly expresses her view that, in effect, Reinach's states of affairs are neither concrete nor abstract. ${ }^{3}$

It certainly is right that Reinach (1911) distinguishes states of affairs from both real and ideal entities:

[W]e have to distinguish between objects [...] whether these be real, (like physical things, tones, experiences), or ideal, (like numbers or propositions, or concepts), and states of affairs, as entities of a quite different nature. (1911/1982, p. 338, original emphasis)

However, Concrete and Abstract are exhaustive and mutually exclusive categories. Hence, contrary to what Jaray holds, nothing is neither concrete nor abstract. Thus, whatever Reinach himself says or does not say, his states of affairs are either concrete or abstract. As we shall see in the following section, most of the roles that Reinach attributes to states of affairs presupposes that they are propositional. For this simple reason, I shall hold that they are abstract. (Of course, it may be that Reinach is to be interpreted as - incoherently - holding that states of affairs are somehow both abstract and concrete, perhaps by being abstract in most contexts while concrete in others,

\footnotetext{
${ }^{2}$ It may be noted that, according to Jaray, Reinach was reluctant to give definitions of his terms (ibid., p. 123 n.). Perhaps that is one reason why she does not put more effort into her 'definition' of Reinach's states of affairs.
}

${ }^{3}$ Jaray claims that there is terminological evidence in Reinach to support this view, or at least to support the view that his states of affairs are not abstract. His original text speaks of 'Sphäre' as the domain of his states of affairs. She thinks that Barry Smith is wrong in his 1982 translation to translate this with 'realm' instead of 'sphere': in her view, the former connotes something independent and Platonic with abstracta as inhabitants, whereas the latter does not. Jaray may be right that 'sphere' implies less independence than 'realm'. In any case, there are actually two interrelated issues here, viz. (i) whether or not Reinach's states of affairs are abstract and (ii) whether or not they are independent (of concreta). Jaray denies both that they are abstract and that they are independent. Typically, propositions are held to be both abstract and independent, but for present purposes, it is the denial of abstractness that I want to focus on. For the fact if it is a fact - that they are dependent on concreta is perfectly compatible with their being abstract. Consider, for instance, how sets of concreta are dependent on their members. 
but this is a purely exegetical question and as such not something we shall consider in the present paper. $\left.{ }^{4}\right)$

Reinach is not alone in having an ontology of states of affairs as propositional and hence as abstracta. As mentioned already, Chisholm (e.g. 1970; 1971) is a well-known proponent of this view. How does Reinach's position compare and contrast with Chisholm's? Chisholm holds that both propositions, and events, are species of states of affairs. While this claim makes immediate sense for propositions, it might seem surprising for events. We normally and correctly think of events as concrete, but if Chisholm has in mind event types, it is not implausible for him to hold that 'events' are a species of states of affairs. At any rate, unlike Reinach, Chisholm further relates his ontology of states of affairs to truth: propositions that are true are facts; a proposition is true iff it obtains; hence, a species of states of affairs are facts. Chisholm further differentiates 'propositions in the broad sense' and 'propositions in a more narrow sense', the former being objects of propositional attitudes, and the latter being those that laws of logic apply to (1970, pp. 19-20). In contrast, Reinach is careful not to attribute truth-values to his states of affairs, cf. fn. 2 below, which suggests he wants to keep them separate from propositions. On the other hand, to repeat, I hold that most of the roles he attributes to them, to be described in the following section, clearly matches a view of states of affairs as propositional. This is thus the case despite their not including the role of being bearer of truth-values.

All in all, I think we can draw the following conclusion. Firstly, despite Jaray's claim and for systematic reasons, Reinach's states of affairs are abstract, just like Chisholm's states of affairs are. Hence, they are also propositional. Secondly, they resemble propositions less than Chisholm's states of affairs (which, to repeat, have propositions as a species, and therefore even are a kind of proposition). Reinach's states of affairs are less propositional than Chisholm's, as it were; but this difference does not interfere with their ability to play Reinach's central roles for states of affairs, in the way I shall now outline.

\footnotetext{
${ }^{4}$ See e.g. Smith (1987, pp. 200-202) for discussion of a corresponding tension in Reinach's conception of states of affairs between his Platonism and his aim that they be non-abstract.
} 


\section{The roles of Reinach's states of affairs}

Reinach holds that his states of affairs play five central roles. Let us briefly consider each of them with special regard to how they relate to Armstrongian SOA-ontology. Here is the first one:

(1) 'States of affairs are objectual correlates of assertion and belief' (1911/1982, p. 336).

One would think that this role amounts to the function that states of affairs are objects of propositional attitudes. Reinach speaks mainly of judgements (assertions), but his view generalises to other mental states, including 'presentations and acts of meaning', as pointed out by Chrudzimski (2012, p. 118). By contrast, Reinach insists that states of affairs, different from propositions, are what is believed, and similarly for other propositional attitudes. As he puts it: '[States of affairs] are, in opposition to objects [including propositions], that which is believed or asserted in judgments' (1911/1982, p. 338). It would perhaps be unacceptably uncharitable to hold that Reinach confuses states of affairs and propositions, despite his own words to the contrary, but certainly this first role is an indirect prima facie argument that his states of affairs are very similar to propositions. As we shall see shortly, his fifth role resembles this first one, and it appears that it ought to be subsumed by it. Consider in any case the second role:

(2) 'States of affairs stand in relations of ground and consequent' (1911/1982, p. 338).

This is a role that Chrudzimski calls being 'terms of logical relations' (2012, p. 118). By contrast, in analytic metaphysics, 'ground' (as in 'grounding') is mostly used for an ontological relation. But we need not dwell on this point of difference here. For 'terms of logical relations' are, intuitively, propositions rather than states of affairs: as it stands, this role is therefore not very relevant to Armstrongian SOA-ontology. This may or may not be the case for the third role,

(3) 'States of affairs may suffer modalities' (1911/1982, p. 338),

for in analytic metaphysics it is contentious whether or not bearers of modal features, including possibility, necessity and probability, are concrete states of affairs. Personally, I am inclined to hold that these are features of propositions - or truth-bearers - and they do not really obtain at the level of truthmakers. If this is right, this is a further indirect prima facie argument that Reinach's states of affairs are propositions. But of course, if modal realism, say in Lewis's version (1986), is true, possibility and necessity are (reducible to) concrete entities; and if a realist ontology of 
probability is correct, e.g. in the shape Mellor's metaphysics of chance (1995, pp. 44-51), the same holds for this modality. In short, this role in itself seems neither to support nor to detract from the view that Reinach's states of affairs are propositions or proposition-like.

Consider at any rate now Reinach's fourth role:

(4) 'States of affairs may be either positive or negative, subsistent or non-subsistent' (1911/1982, p. 339).

That is, on the one hand, Reinach's states of affairs are either positive or negative - call this feature their 'ontic bivalence'. On the other hand, they are either factual or non-factual, as I shall follow Chrudzimski (2012) in calling it. I shall look at their ontic bivalence in some detail below; but the latter feature I shall not discuss in the present paper, though I shall later employ it to rank and classify ontologies of states of affairs with regard to abundance vs. sparseness and which kinds of state of affairs they posit. Of course, the duality of ontic bivalence has a non-ontological counterpart in the feature of truth-value of propositions - and, as we saw above, Reinach is careful not to commit the 'category-mistake' of attributing the latter feature to his states of affairs. ${ }^{5}$

Finally, Reinach ascribes a further cognitive function to states of affairs, which, as mentioned, is similar to the first role, and which I shall state as follows:

(5) States of affairs are apprehended (cf. 1911/1982, pp. 341-343).

This role contrasts with the epistemic relation we have to things: 'Objects are seen or looked at, states of affairs, in contrast, are discerned or apprehended' (ibid., p. 343, original emphasis). However, it appears slightly superfluous to distinguish this role from the first one. True, apprehension is veridical, which assertion and belief need not be. But it is factors extrinsic to the relationship of apprehension, such as whether a belief is justified or true, which determine whether or not a Reinachian state of affairs it is a relatum of an apprehension relation. At any rate, this final role is not one I shall consider further here, any more than the first one is.

In short, for the purposes of this paper, it is thus strictly speaking only Reinach's fourth role that is relevant to Armstrongian SOA-ontology. So, let us next take a closer look at this role,

\footnotetext{
${ }^{5}$ By contrast, according to Barry Smith in his text critical note on Reinach (1911, n. 21), Meinong at times attributes truth-values to his states of affairs (Objektiven), thereby displaying his conflation of propositions with states of affairs.
} 
making sure that, for the sake of argument, we try to consider Reinach's states of affairs 'as if' they could compete for this role with Amstrongian states of affairs.

\section{Ontic bivalence and mode of existence}

As we have seen, according to Reinach's fourth role for his states of affairs, they vary with regard to mode of existence: they can be positive or negative on the one hand; and factual or non-factual on the other. Of these, states of affairs that are positive and factual are the least contentious, and those that are both non-factual and negative are the most controversial. It should be stressed that Reinach does not hold that the contested states of affairs have less existence or that they are somehow subjective, or both. As Crudzimski puts it:

[W]e have [in Reinach] an extremely Platonic approach. His claim would be that, beside the (real and ideal) nominal objects, we must introduce states of affairs. Some of them are positive, some negative. Some of them obtain, some do not. But even the negative and non-obtaining states of affairs are "objective" entities in the sense that they are absolutely independent of any mental activity. (2012, p. 107)

In that sense, Reinach's ontology of states of affairs has only one mode of existence. More to the point here, he does not hold that positive and negative states of affairs have different modes of existence. Now, I shall grant Reinach the implied notion of mode of existence so that these two kinds of states of affairs can be said to have the same mode of existence: that is why I instead speak of the 'ontic (bi)valence' of Reinach's states of affairs. However, I shall depart from his (or Chrudzimski's) implied terminology regarding the second aspect of the role: I shall maintain that factual (obtaining) states of affairs enjoy a different mode of existence than non-factual (nonobtaining) states of affairs. This gives us a simple hierarchy of four options with the most abundant ontology at the top and the sparsest one at the bottom, as follows:

\section{Abundant Level (Reinach): positive, negative, factual and non-factual}

(1) Positive \& Factual

Example: Edinburgh's being north of London

(2) Positive \& Non-Factual

Example: London's being north of Edinburgh 
(3) Negative \& Factual

Example: There being no Artic penguins ${ }^{6}$

(4) Negative \& Non-Factual

Example: There being no Antarctic penguins

A less abundant view, occupying an intermediate level, is obtained if one rejects negative states of affairs but accepts non-factual ones:

\section{Non-Tractarian Intermediate Level: positive, factual and non-factual}

(1) Positive \& Factual

Example: Edinburgh's being north of London

\section{(2) Positive \& Non-Factual}

Example: London's being north of Edinburgh

I use the adjective 'non-Tractarian' here as a convenient marker for this level due to the acceptance of negative states of affairs and rejection of non-factual ones in the Tractatus. This level is unacceptable for Armstrongian SOA-ontology: non-factual states of affairs are merely possible states of affairs, and merely possible entities in my view do not exist. This of course is a controversial view, but it is beyond the scope of this paper to defend it. In any case, a second intermediate level is obtained by rejecting non-factual states of affairs, but accepting negative ones:

\footnotetext{
${ }^{6}$ This is an apparent example of a genuine negative state of affairs. By contrast, the kind of example Reinach usually gives of a putative negative state of affairs, such as the red rose's not being white (1911/1982, p. 340 ), is in my view unlikely to be a proper negative state of affairs. For, unlike my kind of example, it is entailed by the positive state of affairs of the rose's being red. It may well be a genuine negative proposition, of course; but recall that, for the sake of argument, I now consider Reinach's states of affairs to diverge from propositions.
} 
Tractarian Intermediate Level (Armstrong?): positive, negative and factual

(1) Positive \& Factual

Example: Edinburgh's being north of London

\section{(2) Negative \& Factual}

Example: There being no Artic penguins

This level may, in a sense to be qualified in the following section, be Armstrong's or an Armstrongian view. Finally, the least abundant level is obtained by only accepting positive and factual states of affairs:

\section{Sparse Level: positive and factual ${ }^{7}$}

\section{(1) Positive \& Factual}

Example: Edinburgh's being north of London

It should be noted that 'abundant' and 'sparse' in this context carry with them an implication of values in an ontological economy, with abundant ontologies being less parsimonious than sparse ones. Given 'Lewis's Razor' - the principle of ontological economy that, first and foremost, we should not multiply kinds of entity (as opposed to instances of those kinds) beyond necessity (Lewis 1973) - a sparse ontology is, other things being equal, preferable to a competing, abundant one. However, the 'other things being equal'-qualification includes the assumption that the competitors explain the explananda at issue equally well. Of course, the ranking in itself tells us nothing about whether or not they do that.

Corresponding to this hierarchy, we can classify the positions in it according to which kinds of state of affairs they posit, as summarized in this 2 x 2 matrix:

\footnotetext{
${ }^{7}$ Chrudzimski (2012), in effect, ascribes this view to Roman Ingarden, but I shall not consider Ingarden's state of affairs ontology in the present paper.
} 


\begin{tabular}{|l|l|l|}
\hline State of affairs & \multicolumn{1}{|c|}{ Factual } & \multicolumn{1}{c|}{ Non-factual } \\
\hline Positive & $\begin{array}{l}\text { Reinach } \\
\text { Wittgenstein } \\
\text { Armstrong }\end{array}$ & Reinach \\
\hline Negative & $\begin{array}{l}\text { Reinach } \\
\text { Wittgenstein } \\
\text { Armstrong? }\end{array}$ & Reinach \\
\hline
\end{tabular}

Fig. 1

\section{Armstrongian state of affairs ontology and negative states of affairs}

So, to find out where exactly Armstrong's or an Armstrongian SOA-ontology is situated in our hierarchy and classification, let us turn to negative states of affairs. Negative states of affairs face two immediate problems. Firstly, they offend against a strong intuition that there are no negative entities. Indeed, most philosophers have a kind of horror vacui for negative states of affairs, and famously, Russell relates how it 'nearly caused a riot' when he proposed the existence of negative states of affairs (facts) in his lectures on logical atomism at Harvard (1918/1972, p. 67). Secondly, by Lewis's Razor, they need to earn their keep. However, according to Armstrong and Armstrongian SOA-ontology, the question of whether or not there are negative states of affairs is ultimately a question of truthmaking. Specifically, it is a question of whether or not negative states of affairs are required to make true negative truths, such as 'There are no Artic penguins' and 'There are no red roses in the garden'. But this presents us with a dilemma. One the one hand, we maintain that

(TE) Every true claim about the world is made true by something that exists.

On the other hand, in line with the horror vacui of the negative, we like to hold that

(PE) Everything that exists is positive.

Armstrong proposes totality states of affairs as the resolution to the predicament. A totality state of affairs is the state of affairs (fact) that some entities are all the entities. Totality states of affairs can indeed make true negative truths. Consider e.g. 'There are no Arctic penguins'. The truthmaker 
of this can be the plurality or sum of the Arctic animals conjoined with the totality state of affairs that they are all the Arctic animals. Or consider 'This liquid is odourless'. Its truthmaker can be the plurality or sum of all the positive (first-order) states of affairs about the liquid conjoined with the totality state of affairs that they are all the positive states of affairs about the liquid. Notice that the first totality states of affairs involves a totality of substances, whereas the second involves a totality of (first-order) states of affairs about substances (stuff). For our purposes, the difference between these two kinds of totality states of affairs can be ignored. However, these preliminary descriptions still tell us little about the ontology of totality states of affairs (the locution 'the state of affairs that they are all...' is not ontologically very informative).

So Armstrongian SOA-ontology ought to provide an assay of totality states of affairs. Armstrong outlines one such analysis (1997, pp. 197-201), but since at many points he fails to be explicit, we need to conjecture a fair amount of it. The resulting assay is as follows: a totality state of affairs is a sui generis external and formal 'relation of totalling', as he calls it (or T-relation, as I shall abbreviate it), holding between the aggregate of lower-order entities, whether states of affairs or particulars, and their general genus (their summum genus; their 'highest genus'). As an example involving objects, he mentions this: 'The property of being an electron stands in the converse of the T relation to that aggregate that happens to be the totality of electrons.' (1997, p. 199). ${ }^{8}$ Consider as an example of a totality state of affairs involving other states of affairs, the totality state of affairs that the states of affairs $s_{1}, \ldots, s_{n}$ are all the states of affairs. Let us write the aggregate or conjunction of these states of affairs as $\left[\mathrm{s}_{1}, \ldots, \mathrm{s}_{\mathrm{n}}\right]$. The highest genus of these states of affairs is the property of being a state of affairs. The totality state of affairs is then this: T(being a state of affairs, $\left.\left[\mathrm{s}_{1}, \ldots, \mathrm{s}_{\mathrm{n}}\right]\right)$. There is a thorny issue of whether this assay commits us to one big, global totality state of affairs or many, local ones. I am uncertain about the matter: like Armstrong, all I am prepared to claim is that we need 'at least one' totality state of affairs.

Fortunately, however, the only question that need concern us here is whether totality states of affairs are or positive or negative. It is true that Armstrong explicitly proposes them as adhering

\footnotetext{
${ }^{8}$ Armstrong speaks interchangeably of 'aggregate of' and 'conjunction of' the relevant first-order entities, and he seems to mean 'sum' by the former. This need not concern us here. Furthermore, there is a difference between sums and pluralities of these first-order entities, but this we can for simplicity ignore for our present purposes.
} 
to (PE), but is he right in this assumption? Molnar (2000, p. 81) is adamant that he is not: tea's being all there is on the table, to use his homely example, is the same state of affairs as there being nothing that is both not tea and on the table. ${ }^{9}$ Upholding (PE), Molnar therefore rejects them. By contrast, Armstrong, though not wavering in his endorsement of ('at least one' of) them, is equivocal about their status: on the one hand, he believes they are the desired positive truthmakers for negative truths, required by (PE) and (TE); on the other, he nonetheless claims that, in a sense, they are negative states of affairs: he says they are 'no more' states of affairs, and tries to 'excuse' them by citing Spinoza's claim that all determination is negation. From this it might seem that he thinks totality states of affairs are negative only in a kind of Pickwickian sense; that they are not really negative. However, in his reply to an argument of C. B. Martin's, which we need not go into here, he says explicitly that totality states of affairs are 'a species of negative states of affairs' (1997, p. 200). But it is plain that if totality states of affairs are a species of negative facts, then they are negative. Why then, one might ask, postulate totality states of affairs in the first place? Armstrong considers this objection and replies - in my view, correctly - that they are preferable to the paradigmatic negative states of affairs, such as there being no Arctic penguins or this liquid's being odourless: they make such states of affairs supervenient. I think this is agreeable for reasons of ontological economy, since, as I have argued elsewhere Meinertsen (forthcoming), supervenient entities are not included in the expenses included in the accountancy of Lewis's Razor.

In short, we can conclude that Armstrong's or Armstrongian SOA-ontology does include negative states of affairs, namely, totality states of affairs (or at least one of them). As such it clearly does not belong to the sparsest level in our above ranking of state of affairs ontologies. On the other hand, however, in virtue of its rejection of paradigmatic negative states of affairs, it seems it cannot properly be ranked with the Tractarian intermediate view either. Instead, it seems it straddles the two levels, with perhaps most of its weight on the sparsest leg.

\section{Concluding remarks}

If what I have argued in this paper is correct, Reinach's states of affairs are in several respects similar to propositions, notably by being abstract, yet not as much as Chisholmian states of affairs

\footnotetext{
${ }^{9}$ Note that the equivalence $(\forall \mathrm{x})(\mathrm{Fx}) \leftrightarrow \sim(\exists \mathrm{x})(\sim \mathrm{Fx})$ lends credence to this identification, although asserting an identity of course is going further than asserting an equivalence.
} 
are. Despite this, (part of) one of his central roles for states of affairs, viz. their ontic bivalence, is highly pertinent to Armstrongian state of affairs ontology. Firstly, it enables us to rank and classify this and other ontologies of states of affairs according to which kinds of state of affairs they allow - and hence how abundant or sparse they are in that respect. Reinach's ontology is at the top of this grading (though for economical reasons, this may be a vice rather than a virtue). Secondly, it prompts us to ask if the Tractarian acceptance of negative states of affairs is mandatory for Armstrongian SOA-ontology. After having outlined a theory of totality states of affairs, I argued that in a sense it is, since these states of affairs are negative (although less so than paradigmatic negative states of affairs, as it were). Thus, Armstrongian state of affairs ontology does not really belong to the sparsest level in our ranking, but instead is one step closer to Reinach's abundant level that one might have expected. ${ }^{10}$

\footnotetext{
${ }^{10}$ For comments on earlier drafts of this paper, or discussion of its key issues, I would like to thank Javier Cumpa, Peter Simons and Erwin Tegtmeier.
} 


\section{References}

Armstrong, D. M. (1997). A world of states of affairs. Cambridge: Cambridge University Press.

Betti, A. (2015). Against facts. Cambridge, Mass.: MIT Press.

Chisholm, R. (1970). Events and propositions. Nous, 4, 15-24.

Chisholm, R. (1971). States of affairs again. Nous, 5, 179-189.

Crudzimski, A. (2012). Negative states of affairs. Symposium, 16, 106-127.

Dubois. J. M. (1995). Judgment and Sachverhalt: An introduction to Adolf Reinach's phenomenological realism. Dordrect: Springer.

Jaray, K. (2007). Adolf Reinach's contribution to the early phenomenological movement, $\mathrm{PhD}$ thesis, Wilfrid Laurier University.

Lewis, D. (1973). Counterfactuals. Oxford: Blackwell.

Lewis, D. (1986). On the plurality of worlds. Oxford: Blackwell.

Meinertsen, B. R. (2018). Metaphysics of states of affairs: truthmaking, universals, and a farewell to Bradley's regress. Singapore: Springer.

Meinertsen, B. R. (forthcoming). Mellor's question: Are determinables properties of properties or of particulars? American Philosophical Quarterly.

Mellor, D. H. (1995). The facts of causation. London: Routledge.

Molnar, G. (2000). Truthmakers for negative truths. Australasian Journal of Philosophy, 78, 72-86.

Reinach, A. (1911/1982) On the theory of the negative judgement. (B. Smith, Trans.). In B. Smith (Ed.) Parts and moments: Studies in logic and formal ontology, pp. 315-377, Munich: Philosophia Verlag.

Russell, B. (1918). The philosophy of logical atomism. (Reprinted in Russell's logical atomism, pp. 31-142, by D. Pears, Ed., 1972, London: Fontana/Collins).

Smith, B. (1987). On the cognition of states of affairs. In K. Mulligan (Ed.) Speech act and Sachverhalt: Reinach and the foundations of realist phenomenology, pp. 189-225, Dordrecht: Martinus Nijhoff. 